\title{
PENINGKATAN KUALITAS HIDUP LANJUT USIA (LANSIA) DI KOTA DEPOK DENGAN LATIHAN KESEIMBANGAN
}

\author{
Stefanus Mendes Kiik ${ }^{1 *}$, Junaiti Sahar ${ }^{2}$, Henny Permatasari ${ }^{2}$ \\ 1. Maranatha Kupang School of Health Science, East Nusa Tenggara, Indonesia \\ 2. Faculty of Nursing Universitas Indonesia, Depok 16424, Indonesia \\ *E-mail: stefanusmendeskiik@ymail.com
}

\begin{abstract}
Abstrak
Kualitas hidup lansia dipengaruhi berbagai faktor seperti kesehatan fisik, kesehatan psikologis, hubungan sosial dan lingkungan. Penelitian ini bertujuan mengetahui pengaruh latihan keseimbangan terhadap kualitas hidup lansia di Kota Depok. Penelitian quasi experiment ini dilakukan pada dua kelompok; 30 lansia sebagai kelompok kontrol dan 30 lansia sebagai kelompok perlakuan. Teknik pengambilan sampel yang digunakan adalah multistage random sampling. Hasil penelitian menunjukkan bahwa latihan keseimbangan berpengaruh signifikan, meningkatkan kualitas hidup lansia ( $\mathrm{p}<0,001)$. Hal ini disebabkan karena latihan keseimbangan dapat meningkatkan kesehatan fisik, kesehatan psikologis, hubungan sosial dan lingkungan. Latihan keseimbangan lansia dapat digunakan sebagai salah satu upaya untuk meningkatkan kualitas hidup pada lansia di komunitas. Penelitian selanjutnya dapat melakukan penelitian pada kelompok usia yang berbeda untuk mengetahui keefektifan latihan keseimbangan lansia.
\end{abstract}

Kata Kunci: lansia, latihan keseimbangan, kualitas hidup

\begin{abstract}
Quality Improvement of Elderly Life in Depok City with Balance Exercise. The quality of life (QOL) of the older adult is affected by various factors such as physical health, psychological health, social relationships and environment. This study aimed to investigate the effect of balance exercise on quality of life among older adults. This quasi-experimental design included two groups; 30 subjects as intervention groups and 30 subjects as control groups. The sample was taken by multistage random sampling. There were significant improvements in quality of life among older adults ( $p<0,001)$. Balance exercise can improve physical health, psychological health, social relationships, and environment. Balance exercise can be utilized as one of the preventive efforts to increase the quality of life among older adults in the community. Further research may consider a variety of age to know the effectiveness of balance exercise.
\end{abstract}

Keywords: balance exercise, older adult, quality of life

\section{Pendahuluan}

Populasi lansia meningkat sangat cepat. Tahun 2020, jumlah lansia diprediksi sudah menyamai jumlah balita. Sebelas persen dari 6,9 milyar penduduk dunia adalah lansia (WHO, 2013). Populasi penduduk Indonesia merupakan populasi terbanyak keempat sesudah China, India dan Amerika Serikat. Menurut data World Health Statistic 2013, penduduk China berjumlah 1,35 milyar, India 1,24 milyar, Amerika Serikat 313 juta dan Indonesia berada di urutan keempat dengan 242 juta penduduk (WHO, 2013). Menurut proyeksi Badan Pusat Statistik (2013) pada 2018 proporsi penduduk usia 60 tahun ke atas sebesar 24.754.500 jiwa (9,34\%) dari total populasi.

Lansia merupakan salah satu kelompok atau populasi berisiko (population at risk) yang semakin meningkat jumlahnya. Allender, Rector, dan Warner (2014) mengatakan bahwa populasi berisiko (population at risk) adalah kumpulan orang-orang yang masalah kesehatannya 
memiliki kemungkinan akan berkembang lebih buruk karena adanya faktor-faktor risiko yang memengaruhi. Stanhope dan Lancaster (2016) mengatakan lansia sebagai populasi berisiko ini memiliki tiga karakteristik risiko kesehatan yaitu, risiko biologi termasuk risiko terkait usia, risiko sosial dan lingkungan serta risiko perilaku atau gaya hidup.

Stanhope dan Lancaster (2016) mengungkapkan bahwa risiko biologi termasuk risiko terkait usia pada lanjut usia yaitu terjadinya berbagai penurunan fungsi biologi akibat proses menua. Risiko sosial dan lingkungan pada lanjut usia yaitu adanya lingkungan yang memicu stres. Aspek ekonomi pada lansia yaitu penurunan pendapatan akibat pensiun. Risiko perilaku atau gaya hidup seperti pola kebiasaan kurangnya aktivitas fisik dan konsumsi makanan yang tidak sehat dapat memicu terjadinya penyakit dan kematian. Miller (2012) dalam teorinya functional consequences mengatakan penurunan berbagai fungsi tubuh merupakan konsekuensi dari bertambahnya usia.

Lansia identik dengan berbagai penurunan status kesehatan terutama status kesehatan fisik. Berbagai teori tentang proses menua menunjukkan hal yang sama. Status kesehatan lansia yang menurun seiring dengan bertambahnya usia akan memengaruhi kualitas hidup lansia. Bertambahnya usia akan diiringi dengan timbulnya berbagai penyakit, penurunan fungsi tubuh, keseimbangan tubuh dan risiko jatuh. Menurunnya status kesehatan lansia ini berlawanan dengan keinginan para lansia agar tetap sehat, mandiri dan dapat beraktivitas seperti biasa misalnya mandi, berpakaian, berpindah secara mandiri. Ketidaksesuaian kondisi lansia dengan harapan mereka ini bahkan dapat menyebabkan lansia mengalami depresi. Hasil penelitian Brett, Gow, Corley, Pattie, Starr, dan Deary (2012) menunjukkan bahwa depresi merupakan faktor terbesar yang memengaruhi kualitas hidup $(\mathrm{p}=0,000)$. Beberapa hal tersebut dapat menyebabkan menurunnya kualitas hidup lansia.
Latihan fisik sangat penting bagi lansia dalam meningkatkan kualitas hidup. Latihan yang teratur dapat meningkatkan hubungan sosial, meningkatkan kesehatan fisik dan kesehatan mental. Latihan juga berperan penting dalam mengurangi risiko penyakit dan memelihara fungsi tubuh lansia (Ko \& Lee, 2012). Latihan dapat mencegah kelelahan fisik karena meningkatkan fungsi kardiovaskuler, sistem saraf pusat, sistem imun dan sistem endokrin. Latihan juga dapat menurunkan gejala depresi (Chung, 2008).

Berbagai penelitian tentang efektivitas latihan keseimbangan telah dilakukan. Namun hanya sedikit penelitian yang dilakukan untuk mengetahui efektivitas latihan keseimbangan terhadap kualitas hidup lansia. Oleh karena itu, penelitian ini dilakukan dengan tujuan untuk mengetahui pengaruh latihan keseimbangan terhadap kualitas hidup lansia di Kota Depok.

\section{Metode}

Desain penelitian yang digunakan pada penelitian ini adalah quasi experiment dengan pendekatan pre and post with control group design. Teknik sampling yang digunakan dalam penelitian ini adalah multistage random sampling. Teknik pemilihannya sebagai berikut; dari 11 kecamatan di Kota Depok dipilih secara acak yaitu, Kecamatan Pancoran Mas; Kelurahan Pancoran Mas terpilih sebagai kelompok kontrol; Kelurahan Depok Jaya terpilih sebagai kelompok intervensi (perlakuan); RW 01 terpilih dari 21 RW di Kelurahan Pancoran Mas sebagai kelompok control; RW 02 terpilih dari 14 RW di kelurahan Depok Jaya sebagai kelompok perlakuan. Sampel berjumlah 60 lansia (30 kontrol dari Pancoran Mas dan 30 perlakuan dari Depok Jaya).

Kriteria inklusi pada penelitian ini adalah bersedia menjadi responden, berusia 60-74 tahun, mampu berjalan, tidak menggunakan alat bantu jalan, dapat membaca dan menulis, Mini Mental State Exam (MMSE) lebih dari 23, tidak 
mengalami gangguan penglihatan, tidak mengalami gangguan pendengaran, tidak mengalami hipotensi postural, tidak mengikuti senam rutin.

Latihan keseimbangan yang dilakukan lansia terdiri dari 8 gerakan utama yaitu: (1) pemanasan; (2) memutar bahu; (3) berjalan menyamping; (4) berjalan menyilang; (5) berjalan dengan tumit dan jari; (6) berdiri satu kaki; (7) bangun dari duduk; (8) pendinginan. Latihan ini dimodifikasi dari National Health ServicesUnited Kingdom (NHS-UK) dan Center for Disease Control and prevention (CDC). Latihan keseimbangan ini dilakukan 2 kali seminggu yaitu hari senin dan rabu setiap pukul 09.00 WIB selama delapan minggu. Setiap latihan berdurasi 30 menit dengan masing-masing pemanasan dan pendinginan dilakukan selama 5 menit.

Kualitas hidup pada lansia diukur dengan menggunakan WHOQOL-BREF. Instrumen ini mengukur 4 komponen penting yaitu komponen fisik, psikologis, hubungan sosial dan lingkungan (WHO, 2012a). Instrumen ini terdiri dari 26 item pertanyaan yang telah mewakili komponen-komponen yang akan diukur dari kualitas hidup. Kuesioner ini menggunakan skala Likert dengan rating scale dari 1-5. Terdiri dari 26 item pertanyaan (WHO, 2012b). Caballero, et al. (2013) mengatakan instrumen WHOQOL memiliki reliabilitas yang ditunjukkan oleh nilai Cronbach's alpha antara $0,84-0,88$. Nilai validitas menunjukkan nilai $r=0,75$. Penelitian ini telah lolos uji etik oleh komite etik keperawatan Universitas Indonesia. Nomor lolos uji etik adalah 0205.UN2.F12.D/HKP.02.04/2015.

Analisis data menggunakan perangkat lunak analisis data. Paired t-test (dependent t-test) digunakan untuk membandingkan kualitas hidup sebelum dan sesudah perlakuan baik pada kelompok perlakuan maupun kontrol sedangkan uji $t$-independent (pooled $t$-test) digunakan untuk menganalisis beda mean setelah perlakuan pada kelompok perlakuan dan kontrol (Dahlan, 2009).

\section{Hasil}

Rerata kualitas hidup lansia pada kelompok perlakuan sesudah perlakuan lebih tinggi 6,10 dibandingkan dengan sebelum. Hasil uji lebih lanjut menggunakan paired t-test didapatkan nilai $\mathrm{p}<0,001$. Hal ini menunjukkan peningkatan kualitas hidup pada lansia sesudah diberikan latihan keseimbangan. Rerata kualitas hidup lansia pada kelompok kontrol lebih rendah 0,83 dibandingkan dengan sebelum perlakuan. Hasil uji lebih lanjut menggunakan paired $t$-test didapatkan nilai $\mathrm{p}=0,147$. Hal ini menunjukkan bahwa tidak ada perbedaan yang

Tabel 1. Beda Mean dan Signifikansi Sebelum dan Sesudah Intervensi pada Kedua Kelompok

\begin{tabular}{ccc}
\hline Kelompok & Beda Mean & p \\
\hline Perlakuan & 6,10 & $<0,001$ \\
Kontrol & $-0,83$ & 0,147 \\
\hline
\end{tabular}

Tabel 2. Pengaruh Latihan Keseimbangan terhadap Kualitas Hidup Lansia di Kota Depok

\begin{tabular}{ccccc}
\hline Kelompok & Mean & SD & 95\% CI & p \\
\hline Perlakuan $(\mathrm{n}=30)$ & 68,39 & 9,01 & $65,02-71,75$ & \\
Kontrol $(\mathrm{n}=30)$ & 54,22 & 8,17 & $51,17-57,27$ & $<0,001$ \\
\hline
\end{tabular}

*SD: Standar Deviasi 
bermakna pada rerata kualitas hidup lansia sesudah memperoleh latihan keseimbangan pada kelompok kontrol.

Hasil uji statistik menggunakan independent $t$ test untuk membandingkan pengaruh latihan keseimbangan antara kelompok perlakuan dan control. Hasil menunjukkan adanya perbedaan bermakna $(\mathrm{p}<0,001)$.

\section{Pembahasan}

Latihan keseimbangan meningkatkan kualitas hidup lansia. Hal ini sejalan dengan Hewitt, Refshauge, Goodall, Henwood, dan Clemson (2014) menyebutkan bahwa latihan keseimbangan yang dilakukan terhadap 300 lansia selama enam bulan di Australia menunjukkan adanya pengaruh yang signifikan terhadap kualitas hidup lansia di panti. Kualitas hidup yang menurun akibat penuaan dapat ditingkatkan dengan latihan ini. Santos, Dantas, dan Moreira (2011) mengatakan bahwa latihan yang salah satunya berisi latihan keseimbangan yang dilakukan oleh 323 lansia perempuan (rerata 69 tahun) dapat meningkatkan kualitas hidup sebesar 9,19\% (p=0,001).

Penelitian yang dilakukan oleh McAuley, et al. (2012) menunjukkan bahwa latihan keseimbangan yang dikombinasikan dengan fleksibilitas dan toning atau FlexToBa ${ }^{\mathrm{TM}}$ dapat meningkatkan performa fungsional, keterbatasan fungsi tubuh, kualitas hidup. Taracki, Yeldan, Huseyinsinoglu, Zenginler, dan Eraksoy (2013) meneliti 110 lansia (yang dianalisis hanya 99 lansia akibat dropout) dengan sklerosis multipel. Latihan dilakukan selama 12 minggu yang dipandu oleh fisioterapis. Hasil analisis menunjukkan bahwa latihan keseimbangan dapat meningkatkan kualitas hidup lansia $(p=0,006)$. Selanjutnya penelitian yang dilakukan oleh Sun, Aodeng, Tanimoto, Watanabe, dan Han (2015) menyebutkan bahwa untuk meningkatkan kualitas hidup pada lansia di komunitas maka sangat penting dilakukan dengan menjaga kesehatan. Menurut peneliti hal ini dapat dilakukan melalui latihan keseimbangan dan gaya hidup sehat. Park, Han, dan Kang (2014) mengatakan bahwa program latihan pada lansia efektif meningkatkan kualitas hidup, harga diri dan menurunkan gejala depresi. Lai, Leung, Kwong, dan Lee (2015) melakukan penelitian di Hongkong, hasilnya menunjukkan bahwa nyeri merupakan salah satu faktor yang dapat menurunkan kualitas hidup lansia di nursing home resident. Tavares, Dias, Santos, Hass, dan Miranzi (2013) mengatakan bahwa penurunan kualitas hidup disebabkan oleh keterbatasan fungsi tubuh, penyakit, pendidikan, rendahnya pendapatan dan kurang berhubungan dengan orang lain.

Penelitian yang dilakukan oleh Tse, Tang, Wan dan Vong (2014) di Hong Kong menunjukkan pengaruh latihan kekuatan otot, streching dan keseimbangan terhadap nyeri dan kesejahteraan psikososial atau kualitas hidup (kebahagiaan, kesendirian, kepuasan hidup, dan depresi). Rerata usia responden adalah 85,44 tahun. Kelompok perlakuan terdiri dari 225 lansia sedangkan kelompok kontrol terdiri dari 171 lansia. Setelah delapan minggu latihan oleh fisioterapis dan perawat menunjukkan hasil yang signifikan pada kelompok perlakuan dibandingkan dengan kelompok kontrol di mana nyeri menurun $(p<0,05)$. Sedangkan kesejahteraan psikososial/ kualitas hidup meningkat secara signifikan $(\mathrm{p}<0,05)$. Latihan keseimbangan dapat mengkompensasi penurunan fungsi sistem muskuloskeletal. Secara fisiologis, latihan keseimbangan dapat meningkatkan range of motion, kekuatan otot, total kalsium tubuh, memperbaiki koordinasi tubuh, mencegah kehilangan massa otot dan memperbaiki fungsi tubuh (Miller, 2012). Hal ini akan meningkatkan kualitas hidup karena lansia merasa lebih sehat untuk beraktivitas.

Campos, Ferreira, Vargas, dan Albala (2014) melakukan penelitian dengan WHOQOL-BREF terhadap lansia yang tinggal di komunitas di wilayah Brazil menunjukkan bahwa wanita yang memiliki kondisi fisik dan kesehatan psikososial yang baik memiliki kualitas hidup yang lebih tinggi. Sedangkan, pada laki-laki kualitas 
hidup terbaik berhubungan dengan sosial ekonomi yang tinggi dan kondisi fisik serta kesehatan psikososial yang baik. Lansia yang sehat memang memiliki kualitas hidup yang lebih baik. Menurut Strupeit, Wolf-Ostermann, Buss dan Dassen (2014) menunjukkan bahwa QOL lansia yang diukur dengan WHOQOL-BREF saat masuk fasilitas rehabilitasi di Hamburg, Jerman sebesar 57,85 namun setelah enam bulan status fungsinya membaik dan QOL nya menjadi 67,85. Hal ini mendekati QOL pada penelitian tentang latihan keseimbangan.

Penelitian lain dilakukan Alexandre, Cordeiro dan Ramos (2009) pada 120 lansia di Kota Sao Paulo dan Sao Jose dos Campos, bagian tenggara Brazil. Instrumen yang digunakan adalah WHOQOL-BREF. Hasil penelitiannya menunjukkan rerata kualitas hidup lansia pada domain fisik sebesar 62,11. Rerata domain psikologis sebesar 62,22. Rerata domain hubungan sosial sebesar 72,15, sedangkan domain lingkungan sebesar 66,30. Rerata kualitas hidup ini hampir sama dengan rerata kualitas hidup pada penelitian tentang latihan keseimbangan ini. Kesamaan rerata kualitas hidup disebabkan karena status kesehatan fisik dan psikologis yang cenderung sama. Hasil pre-test penelitian tentang Latihan keseimbangan didapatkan rerata domain fisik 64,38. Rerata domain psikologis lansia sebesar 65,42. Rerata domain hubungan sosial lansia 58,33 dan rerata domain lingkungan sebesar 61,04. Perbedaannya terletak pada domain hubungan sosial.

Domain hubungan sosial dan lingkungan pada lansia di wilayah Brazil lebih tinggi dibandingkan dengan lansia di Depok, Indonesia. Hal ini menunjukkan bahwa kualitas hidup lansia di wilayah Brazil dari segi hubungan sosial dan lingkungan lebih baik dibandingkan dengan lansia di Depok, Indonesia. Hal ini disebabkan oleh di wilayah Brazil sistem pelayanan kesehatan yang sudah lebih maju dibandingkan dengan di Indonesia. Dengan adanya latihan keseimbangan yang dilakukan di Brazil memungkinkan para lansia yang sebelumnya sendirian di rumah harus berkumpul dan saling berinteraksi. Lansia yang bertemu dan berinteraksi membuat mereka saling mendukung, memotivasi dan membutuhkan. Lain halnya dengan yang terjadi di negara berkembang, lansia setiap hari selalu bertemu, sering bertegur sapa sehingga aspek hubungan sosial yang mencakup kepuasan terhadap hubungan personal atau sosial dan kepuasan terhadap dukungan dari teman meningkat tidak sebesar peningkatan domain tersebut pada lansia di Brazil (Gomes, et al., 2014). Hal ini berarti hubungan sosial telah menjadi suatu pola kebiasaan di negara berkembang sehingga aspek tersebut tidak terlalu tinggi peningkatannya.

Peningkatan domain lingkungan mencakup merasa aman, kesehatan lingkungan, memiliki cukup uang, ketersediaan informasi, kesempatan untuk bersenang-senang atau rekreasi, kepuasan terhadap kondisi tempat tinggal, kepuasan akan akses layanan kesehatan dan kepuasan terhadap transportasi yang dijalani. Pada lansia di Brazil domain ini cukup tinggi karena lansia lebih sering mengakses layanan kesehatan yang sebelumnya hanya sekali seminggu saat latihan menjadi lebih sering (Gomes et al., 2014). Selain itu, lansia lebih merasa aman karena dekat dengan temannya, berekreasi atau bersenang-senang, informasi yang diperoleh juga meningkat karena lansia bertukar informasi dengan temannya dan kepuasan terhadap akses akan layanan kesehatan juga lebih baik.

Sebaliknya domain fisik dan domain psikologis lebih tinggi pada lansia di Depok. Pengaruh latihan keseimbangan paling besar terhadap peningkatan domain fisik yang terdiri dari penurunan nyeri. Dengan adanya latihan keseimbangan dapat menurunkan nyeri sendi yang dialami lansia. Beberapa lansia mengatakan nyeri yang selama ini dialami berkurang. Penurunan nyeri ini menyebabkan ketergantungan akan obat-obatan menurun. Selain itu, kemampuan lansia untuk melakukan aktivitas sehari-hari meningkat. Lansia mengatakan kemampuan mereka meningkat dalam beberapa aktivitas sehari-hari seperti mengangkat pot bunga, menyapu dan berpakaian. Artinya se- 
cara fisik lansia lebih sehat dibandingkan sebelum mengikuti latihan keseimbangan. Lansia menjadi lebih puas terhadap kemampuan untuk melakukan aktivitas sehari-hari. Hal ini membuat tidur menjadi lebih tenang. Cheon et al. (2014) mengatakan bahwa tidur sangat dipengaruhi oleh kesehatan seseorang. Aktivitas fisik yang teratur sangat baik untuk menjaga kesehatan. Miller (2012) mengatakan melalui gaya hidup yang aktif penurunan fungsi sitem muskuloskelatal dapat dikompensasi. Secara fisiologis, latihan dapat meningkatkan range of motion, peningkatan kekuaatan otot, peningkatan total kalsium tubuh, memperbaiki koordinasi tubuh, mencegah kehilangan massa otot dan memperbaiki fungsi tubuh. Oleh karena itu, latihan keseimbangan sangat bermanfaat bagi lansia.

Latihan keseimbangan juga meningkatkan domain psikologis. Hal ini karena latihan keseimbangan meningkatkan kemampuan berkonsentrasi, meningkatkan penerimaan penampilan tubuhnya, membuat hidup lansia lebih berarti, meningkatkan kepuasan terhadap diri, mengurangi kecemasan, sepi, putus asa, dan depresi. Miller (2012) mengatakan latihan meningkatkan koordinasi neuromuskular. Lansia lebih mampu berkonsentrasi. Marques, Sánchez dan Vicario (2014) menyebutkan 48 lansia yang berpartisipasi dalam penelitiannya di Portugal mengatakan bahwa kualitas hidup berarti memiliki tubuh yang sehat, mendapatkan kedamaian, keharmonisan hidup, merasa bahagia, kepuasan hidup, melakukan kegemaran, terbinanya hubungan dengan teman dan tetangga.

Secara umum latihan keseimbangan meningkatkan kualitas hidup lansia. Peningkatan kualitas hidup lansia ini membuktikan bahwa latihan keseimbangan merupakan salah satu intervensi yang baik untuk diterapkan di komunitas. Mauk (2014) mengatakan bahwa lanjut usia yang sukses adalah mereka yang aktif dan ikut dalam banyak kegiatan. Lansia identik dengan penuaan dan penurunan berbagai fungsi tubuh. Oleh karena itu, agar fungsi tubuh tidak terus menurun lansia perlu melakukan la- tihan keseimbangan sehingga lansia tetap sehat dan berkualitas.

\section{Kesimpulan}

Latihan keseimbangan berpengaruh terhadap kualitas hidup lansia. Kualitas hidup kelompok perlakuan lebih baik dibandingkan dengan kelompok kontrol setelah perlakuan. Kualitas hidup lansia meningkat karena latihan keseimbangan memiliki pengaruh terhadap fungsi fisik, psikologik, hubungan sosial dan lingkungan lansia. Peningkatan domain kualitas hidup yang tertinggi adalah kesehatan fisik dan terendah adalah lingkungan (AF, AYN, TN).

\section{Ucapan Terima Kasih}

Terima kasih kepada Lembaga Pengelola Dana Keuangan (LPDP) yang telah mendanai penelitian ini.

\section{Referensi}

Alexandre, T.S., Cordeiro, R.C., \& Ramos, L.R. (2009). Factors associated to quality of life in active elderly. Rev Saúde Pública, 43 (4), 613-621.

Allender, J.A., Rector, C., \& Warner, K.D. (2014). Community dan public health nursing promoting the public's health (8th Ed.). Philadelphia: Lippincott Williams \& Wilkins

Badan Pusat Statistik (BPS). (2013). Proyeksi penduduk Indonesia population projection 2010 -2035. Jakarta: Badan Pusat Statistik

Brett, C.E., Gow, A.J., Corley, J., Pattie, A., Starr, J.M., \& Deary, I.J. (2012). Psychosocial factors and health as determinants of quality of life in community-dwelling older adults. Qual Life Res, 21, 505-516. doi: 10.1007/ s11136-011-9951-2.

Caballero, F.F., Miret, M., Power, M., Chatterji, S., Tobiasz-Adamczyk, B., Koskinen, S., . . . Ayuso-Mateos, J.L. (2013). Validation of an instrument to evaluate quality of life in the 
aging population: WHOQOL-AGE. Health and Quality of Life Outcomes, 11, 177. doi: 10.1186/1477-7525-11-177.

Campos, A.C.V., Ferreira, E.F., Vargas, A.M.D., \& Albala, C. (2014). Aging, Gender and Quality of Life (AGEQOL) study: Factors associated with good quality of life in older Brazilian community-dwelling adults. Health and Quality of Life Outcomes, 12, 166. doi: 10.1186/s12955-014-0166-4

Cheon, C., Oh, S.M., Jang, S., Park, J.S., Park, S., Jang, B.Y., . . . \& Ko, S.G. (2014). The relationship between health behavior and general health status: Based on 2011 Korea national health and nutrition examination survey. Osong Public Health Res Perspect, 5 (1), 28-33. doi: 10.1016/j.phrp.2013.12. 003.

Chung, H.A. (2008). A literature review a program of intervention of patient geriatric depression. Society of Occupational Therapy for the Aged and Dementia, 2 (1), 59-67.

Dahlan, M.S. (2009). Statistik untuk kedokteran dan kesehatan (edisi ke-4). Jakarta: Salemba Medika.

Hewitt, J., Refshauge, K.M., Goodall, S., Henwood, T., \& Clemson, L. (2014). Does progressive resistance and balance exercise reduce falls in residential aged care? Randomized controlled trial protocol for the SUNBEAM program. Clinical Interventions in Aging, 21 (9), 369-376, doi: 10.2147/CI A.S53931.

Ko, J.E., \& Lee, S.H. (2012). A multilevel modeling of factors affecting depression among older Korean adults. Mental Health \& Social Work, 40 (1), 322-351.

Lai, C.K.Y., Leung, D.D.M., Kwong, E.W.Y., \& Lee, R.L.P. (2015). Factors associated with the quality of life of nursing home residents in Hongkong. International Nursing Review, $62,120-129$.

Marques, E.M.B.G., Sanchez, C.S., \& Vicario, B.P. (2014). Perception of the quality of life of a group of older people. Revista de
Enfermagem Referência, 4 (1), 73-81. doi: 10.12707/RIII1314.

Mauk, K.L. (2014). Gerontological nursing: Competencies for care (3rd Ed.). London: Jones and Bartlett Publishers International.

McAuley, E., Wójcicki, T.R., White, S.M., Mailey, E.L., Szabo, A.N., Gothe, N., . . \& \& Estabrooks, P. (2012). Physical activity, function, and quality of life: Design and methods of the FlexToBa ${ }^{\mathrm{TM}}$ trial. Contemporary Clinical Trials, 33 (1), 228 236. doi: 10.1016/j.cct.2011.10.002.

Miller, C.A. (2012). Nursing for wellness in older adult: Theory and practice (6th Ed.). Philadelphia: Lippincott Williams \& Wilkins.

Park, S.H., Han, K.S., \& Kang, C.B. (2014). Effects of exercise programs on depressive symptoms, quality of life, and self-esteem in older people: A systematic review of randomized controlled trials. Applied Nursing Research, 27 (4), 219-226. doi: 10.1016/j. apnr.2014.01.004.

Santos, C.A.S., Dantas, E.N.M., \& Moreira, M.H.R. (2011). Correlation of physical aptitude; functional capacity, corporal balance and quality of life (QoL) among elderly women submitted to a post-menopausal physical activities program. Archives of Gerontology and Geriatrics, 53(3), 344-349. doi: 10.101 6/j.archger.2010.12.019.

Stanhope, M., \& Lancaster, J. (2016). Public health nursing population centered health care in the community (9th Ed.). Missouri: Elsevier.

Strupeit, S., Wolf-Ostermann, K., Buss, A., \& Dassen, T. (2014). Mobility and quality of life after discharge from a clinical geriatric setting focused on gender and age. Rehabilitation Nursing, 39, 198-206. doi: 10.1002/rnj.117.

Sun, W., Aodeng, S., Tanimoto, Y., Watanabe, M., Han, J., Wang, B., ... Kono, K. (2015). Quality of life (QOL) of the communitydwelling elderly and associated factors: A 
population-based study in urban areas of China. Archives of Gerontology and Geriatrics, 60 (2), 311-316. doi: 10.1016/j.archger.201 4.12.002.

Taracki, E., Yeldan, I., Huseyinsinoglu, B.E., Zenginler, Y., \& Eraksoy, M. (2013). Group exercise training for balance, functional status, spasticity, fatigue and quality of life in multiple sclerosis: A randomized controlled trial. Clinical Rehabilitation, 27, 813-822. doi: $10.1177 / 0269215513481047$.

Tavares, D.M.S., Dias, F.A., Santos, N.M.F., Hass, V.D., \& Miranzi, S.C.S. (2013). Factors associated with the quality of life of elderly men. Rev Esc Enferm USP, 47 (3), 673-680. doi: 10.1590/S0080-623420130000300022.

Tse, M.M.Y., Tang, S.K., Wan, V.T., \& Vong, S.K.S. (2014). The effectiveness of physical exercise training in pain, mobility, and psychological well-being of older persons living in nursing homes. Pain Management Nursing, 15 (4), 778-788. doi: 10.1016/j. pmn.2013.08.003.

WHO. (2012a). WHOQOL Spirituality, religiousness and personal beliefs (SRPB) field-test instrument. Geneva: WHO.

WHO. (2012b). WHOQOL-SRPB users manual scoring and coding for the WHOQOL SRPB field-test instrument. Geneva: WHO.

WHO. (2013). World health statistics 2013. Geneva: WHO press. 